\title{
1. Science, society and a sustainable future
}

\section{Johan Rockström and Nicholas Stern}

The global turbulence triggered by the COVID-19 (coronavirus) pandemic, with abrupt impacts on human lives and widespread deaths, coupled with the fastest and largest downturn of the global economy since World War II, has placed many countries under war-like conditions. On 16 March 2020, President Macron declares that France is at war. On 18 March, President Trump labels himself as a war-time president combating the coronavirus, and on 25 March, PM Narendra Modi announces a 21-day lockdown of India. These are expressions of a state of emergency; a global fight against an abrupt threat to societal stability. And world citizens rose to the challenge, adapting and accepting weeks of quarantine, draconian regulations and surveillance and disruptions of daily lives. In many countries, notwithstanding huge increases in public spending, we see an abrupt loss of jobs, with large risks of long-term damage to economies around the world, particularly severe for developing countries that also face capital flight, declining remittances and falling commodity prices.

A few months before the coronavirus outbreak, the scientific community established the Earth Commission, an independent "IPCC for Earth", with the scientific task of assessing the safe guardrails for a stable planet. ${ }^{1}$ This initiative is led by Future Earth, the global network of researchers and institutions that have provided a significant part of the scientific evidence that the human pressures on Earth are now so large they define a new geological epoch, the Anthropocene. That we today need to call on science to determine a safe operating space on Earth is a reflection of another interconnected emergency: the imminent risk of destabilizing the entire planet.

The entire Earth system is threatened by further destruction of biodiversity, the degrading of our land, forests and oceans, polluting air and water, destabilizing the climate and general devastation of our natural capital. Together they can undermine or destroy the basis for our livelihoods, where and how we can live - indeed, whether many can survive. If these forces are not managed much better, if we do not find better ways of producing and consuming, integrating adaptive capacity and flexibility - that is, resilience - in our social 
and environmental fabric, the consequences could be catastrophic, with widespread loss of life, great movements of people and the likelihood of severe and extended conflict. We are all threatened, but it is the poorest who are hit earliest and hardest.

The scientific community has been warning for many years, not only of the risk of crossing dangerous tipping points on Earth that may trigger unstoppable global warming - like irreversible melting of the Greenland ice sheet, thawing of Siberian permafrost or the slowdown of heat circulation in the Atlantic ocean (AMOC) ${ }^{2}$ - but also of the risks of social-environmental interactions triggering abrupt shocks with large-scale impacts on communities and economies across the world (Homer-Dixon et al., 2015). These include the rising frequency over the past 20 years of outbreaks of zoonotic diseases - for example, Ebola, SARS, MERS and COVID-19, which are a result of the complex interactions of globalized networks of travel and trade, high human density of living, particularly in urban environments, and risky behaviour by human societies (such as wet wildlife markets), colliding with dramatic ecological habitat change due to deforestation and global warming, pushing wild species closer to humans, and, with climate change, changing patterns of migration of birds, implying new interactions (IPBES, 2019; Johnson et al., 2020; Shapiro and McAdams, 2018).

The evidence points in one direction - that the coronavirus crisis is a manifestation of the social and ecological vulnerabilities in the Anthropocene - and it provides ample support for the need to move quickly and decisively to bend the global curves of greenhouse gas emissions and to slow and halt the undermining of the natural ecosystems on Earth rapidly, in only one generation (the coming 20-30 years). In so doing we can transform our world to prosperity and equity within the safe operating space on a stable and resilient planet. At the same time, the Anthropocene also means, now that humanity is the dominant force of change on Earth, that we can collectively determine the future for all. Science, technology and innovation, if they can be guided and put to service in the appropriate direction, can be the means of achieving the sustainable, equitable and resilient future for both people and the planet that so many seek. Societies and economies must change too, including in the ways we work, live and interact and the governance we create.

The scientific support for the compelling need to "grasp our last chance" for climate action and for protecting and enhancing our natural capital of all kinds is overwhelming. Not only in terms of assessing the global risks we face - if we follow our current business-as-usual trajectory we are likely to crash through the $1.5^{\circ} \mathrm{C}$ ceiling by around 2040 or before and $2^{\circ} \mathrm{C}$ by 2050 or soon thereafter - but also in terms of providing an unprecedented clarity on the safe pathway the world must follow: the latest Intergovernmental Panel on Climate Change (IPCC) assessment (SR1.5) shows that global emissions of $\mathrm{CO}_{2}$ must 
start bending in 2020 and be cut globally by half in the coming ten years (until 2030) and reach net zero by 2050 , to have a reasonable chance of staying well below $2^{\circ} \mathrm{C}$ of global warming (compared to pre-industrial global mean temperature) (IPCC, 2018). This requires a global transformation across all sectors of society, from food production to energy supply, transport, construction and production of consumer goods. We are talking about a system-wide transformation that encompasses technology, innovation, governance, finance, business models, equity, values and behavioural change.

The call for the scientific community is surely "loud and clear", across academic disciplines, to work together advancing insights and solutions through interdisciplinary research collaboration. Of critical importance is a closer integration of research on political economy, finance and governance, with Earth system science and climate impact research. Economic policies should build resilience rather than build in brittleness. They should integrate externalities and capture the true risk landscape of fat-tail (high-impact and higher-than-comfortable probability) tipping points. These are policies that can also provide for more equitable distribution of well-being, both within and across generations. The failure to construct such policies has, in large measure, followed from an absence of understanding of how ecosystems work, a short-sighted and narrow view of objectives, and a neglect to address market failure. We can create sound policies, but we must deepen our economic understanding.

Similarly, the world needs to rapidly understand the governance implications of collectively stabilizing not only the warming of oceans and the atmosphere, but also the stability of big biomes, like the boreal forests and rainforests, ice sheets and wetlands, coral reef systems and peat lands. The agenda, of how to govern the global commons within planetary boundaries, can be pursued only through interdisciplinary science between political science and earth system research. And putting such governance into action will require political will within and across communities and nations and enlightened leadership, both of which can be fostered by a deeper understanding of the scientific issues, including the social science.

Making the digital revolution, biotechnology and advances in artificial intelligence work for a stabilized climate, a healthy biosphere and a just future for all is one of the major challenges over the coming decades. In a world of 10 billion people, where all citizens have the same right to a good life, one of our grand challenges is how to manage the remaining carbon and ecological space on Earth, wisely and equitably.

These are some of the frontiers of global sustainability science. As we show in this book, grasping our "last chance" for climate action and natural capital in pace and scale with the scientific necessity, will be possible only if stakeholders in society rise together to these challenges. Those who are indeed rising to 
these challenges include the defenders, litigants, youth, entrepreneurs, investors and communicators of this book. As shown here, there is ample evidence of strong responses, solutions and actions. Unfortunately, they are all too often islands of success in an ocean of indifference at best and of resistance and ignorance at worst.

We believe that change at the pace and scale we need is indeed possible. The coronavirus crisis provides proof of our remarkable ability to rise collectively and rapidly in the face of a global threat. It also reminds us that we must anticipate risk much better than we have done in the past. For the planetary climate and biodiversity threat, we sit on ample evidence that the transformation to a zero-carbon future that protects and nurtures natural ecosystems is more attractive, on all fronts, in terms of the economy, jobs, health, and in terms of building resilience - that is, the capacity to deal with abrupt shocks and surprises in the future. The evidence is clear today that a zero-carbon future is a much better future for humanity, across the full dimensions of well-being. Indeed, the drive to zero carbon is the sustainable, inclusive and resilient growth story of the twenty-first century. In the short run, the necessary investments will increase demand and sharpen supply. In the medium term, we shall see (indeed, are already seeing) the drive to zero carbon bringing discovery, innovation, investment and growth. There is no medium- or long-term high-carbon growth story - an attempt would produce an environment so hostile that it would halt and reverse economic and social development. Further, the new way of producing, consuming and living can be more inclusive, full of new opportunities and bringing greater security in a world with stronger natural capital.

Scientifically, accelerating the path towards generating solutions and relevant insights can be accomplished through closer co-design and co-development of knowledge. Formulating questions and challenges together, between scientists and stakeholders from business, city mayors, policy-makers, community leaders, indigenous voices, provides a co-design of fast-tracking research to tackle urgent real-world problems. Co-developing knowledge, by connecting scientific methodologies of transparency, replicability and uncertainty, with user inter-phases and experience of local behaviour and preferences, coupled to citizen science and big data gathering on citizen knowledge, can further advance and accelerate the knowledge-action interplay on climate management and protection and enhancement of natural capital.

This is where we see the defenders, litigants, youth, entrepreneurs, investors and communicators, as many of the true "heroes of the zero-carbon transition", playing a critical role interacting with science, to generate responses, solutions and positive momentum towards sustainable zero-carbon societies. They understand both the issues and how societies can rise to the great challenges we now face. 
An area where multi-stakeholder action is urgently needed is safeguarding biodiversity and managing ecosystems as critical carbon sinks and sources of human well-being and resilience. Natural ecosystems, on land and in oceans, today sequester (absorb) some 50 per cent of the global emissions of carbon dioxide from fossil-fuel burning and deforestation (Friedlingstein et al., 2019). This is the largest single "subsidy" to the world economy, provided "for free" by the planet. Approximately half this occurs on land, and the latest science shows worrying signs of gradual decline in the carbon sink capacity (Hubau et al., 2020) and uncertainty regarding future sink capacity as the planet gets warmer (IPCC, 2019), with terrestrial ecosystems under multiple pressures such as loss of forest habitats, lowered biomass growth due to increased severity in droughts, disease in forests such as bark beetle outbreaks on temperate forests in Canada, and increased forest fires as in the Amazon and the devastating 2019/20 forest fires in Australia. Further, land degradation diminishes the capture of carbon in the soil. These are indications of how biodiversity loss and degraded ecosystems lead to loss of Earth resilience, resulting in risks of amplified global warming as nature loses its capacity to "be our best friend" by dampening global warming.

Losing biodiversity also puts us in a weaker state in the face of shocks, like droughts and pandemics. According to the latest assessment, in the State of the World's Biodiversity for Food and Agriculture by the United Nations Food and Agriculture Organization (FAO, 2019), of the 6000 plant species humans have cultivated for food, just nine now account for two-thirds of all crop production. There are nearly 8000 local breeds of farm animals still in existence, but global livestock production is today based on only a handful of breeds. At least a quarter of all local breeds are now at risk of extinction. This shows a remarkable development towards monocultures and reliance for food security across the world on very few species. Globally, to put this in perspective, 94 per cent of all biological weight from living animals on Earth is today represented by us humans and our livestock (Bar-On, Phillips and Milo, 2018). Only 6 per cent is the remaining wildlife on Earth, which is in the midst of the sixth mass extinction of species, caused by another species - us (IPBES, 2019). The loss of the genetic diversity in world agriculture makes our food supply, and thereby our future, increasingly vulnerable.

Agriculture is also the largest driver behind deforestation, which reduces natural habitats for wildlife, resulting not only in loss of carbon sinks and ecosystem functions, like moisture recycling for rainfall, but also pushes wildlife out of their normal habitats, closer to human settlements, increasing the risk of zoonotic disease outbreak (Johnson et al., 2020).

The "super-year 2020", when climate action was to be solidified five years after the Paris Agreement, has abruptly turned into the shutdown year 2020, due to the coronavirus crisis. While the pandemic is a "fast" crisis and 
global warming a "slow" crisis, they are both planetary emergencies, which, moreover, are interconnected in the globalized world of the Anthropocene. Recovery after the pandemic will pose tremendous social-economic challenges and requires learning on how to build more resilient societies able to meet planetary health risks. We would argue that the transformations required for a successful outcome on holding the $2^{\circ} \mathrm{C}$ line on global warming (Sachs et al., 2019; TWI2050, 2018) - decarbonize the energy sector, halt biodiversity loss, shift the global food system from carbon source to sink, make the digital revolution work for sustainability, invest in health, wealth and education for all citizens - are integral also to the recovery from the coronavirus pandemic and to reach the UN Sustainable Development Goals. It all integrates into one system-wide agenda for health, equity and prosperity for all humans on Earth. Fundamentally, it requires actions on climate and sustainability to provide the well-being, wealth and resilience we seek and on the basis of which we can navigate our joint future in a world where adverse surprises increasingly form part of normality.

We may have lost some time on climate action in 2020, but we have learnt the hard way - how important it is to build sustainable and resilient economies. We have learnt more about our common humanity and our fragility, about the husbanding of resources, how the world looks with less pollution, that collective action is possible, and that mobilizing human and financial capacities to tackle the great problems is indeed possible. Now is the time to show that we can take on the global climate and ecological crises. The new development path can be enormously attractive; going back to the old one would be profoundly dangerous.

\section{NOTES}

1. See "Earth Commission", accessed 8 August 2020 at https://futureearth.org/ initiatives/earth-targets-initiatives/earth-commission/.

2. Atlantic meridional overturning circulation.

\section{REFERENCES}

Bar-on, Y.M., Phillips, R., and Milo, R. 2018. "The biomass distribution on Earth". Proceedings of the National Academy of Sciences, 115 (25), 6506-11.

Food and Agriculture Organization of the United Nations (FAO). 2019. The State of the World's Biodiversity for Food and Agriculture, edited by J. Bélanger and D. Pilling. Rome: FAO Commission on Genetic Resources for Food and Agriculture Assessments.

Friedlingstein, P., Jones, M.W. and O'Sullivan, M. et al. 2019. "Global carbon budget, 2019”. Earth System Science Data, 11, 1783-838.

Homer-Dixon, T., Walker, B. and Biggs, R. 2015. "Synchronous failure: the emerging causal architecture of global crisis". Ecology and Society, 20(3), article 6. 
Hubau, W., Lewis, S.L. and Phillips, O.L. et al. 2020. "Asynchronous carbon sink saturation in African and Amazonian tropical forests". Nature, 579, 80-87.

Intergovernmental Panel on Climate Change (IPCC). 2018. "Summary for policymakers". In Global Warming of $1.5^{\circ} \mathrm{C}$ : An IPCC Special Report. Edited by V. Masson-Delmotte, P. Zhai and H.-O. Pörtner et al. Geneva: IPCC.

Intergovernmental Panel on Climate Change (IPCC). 2019. "Summary for policymakers". In Climate Change and Land: An IPCC Special Report. Edited by R. Shukla, J. Skea and E. Calvo Buendia. Geneva: IPCC.

Intergovernmental Science-Policy Platform on Biodiversity and Ecosystem Service (IPBES). 2019. Global Assessment Report on Biodiversity and Ecosystem Services. Edited by S. Brondizio, J. Settele and S. Díaz et al. Bonn: IPBES Secretariat.

Johnson, C.K., Hitchens, P.L. and Pandit, P.S. et al. 2020. "Global shifts in mammalian population trends reveal key predictors of virus spillover risk". Proceedings of the Royal Society B: Biological Sciences, 287 (1924), 20192736.

Sachs, J.D., Schmidt-Traub, G. and Mazzucato, M. et al. 2019. "Six transformations to achieve the Sustainable Development Goals". Nature Sustainability, 2, 805-14.

Shapiro, L. and McAdams, H. 2018. "Technological change and global biological disequilibrium”. In Beyond Disruption: Technology's Challenge to Governance. Edited by G.P. Shultz, J. Hoagland and J. Timbie. Stanford, CA: Hoover Institution Press.

The World in 2050 (TWI2050). 2018. Transformations to Achieve the Sustainable Development Goals. Laxenburg: International Institute for Applied Systems Analysis (IIASA). 